\title{
Discussion
}

\section{Transcript of Live Discussion: The Cell Cycle in Alzheimer's Disease: Let's Unite Around Division ${ }^{1}$}

\author{
Live Discussion held 20 May 2002 at 12 noon \\ Posted 31 July 2002 \\ Participants: Inez Vincent, Zsuzsanna Nagy, Rachael Neve, Karl Herrup, Nathaniel Milton, Mark Smith, Ben \\ Wolozin, Yuzhi Chen, Kung Ping Lu, June Kinoshita, Gabrielle Strobel, Jan Hallows, Robert Bowser, Douglas \\ Feinstein, Craig Atwood, Ken Maiese
}

Gabrielle Strobel: Welcome to today's chat on a fascinating hypothesis in Alzheimer's disease (AD). I am managing editor at the Alzheimer Research Forum and will be moderating today. Why do we not start by asking Inez Vincent to restate her hypothesis and say what is most needed now to further test it.

Inez Vincent: The basic hypothesis is that entry of postmitotic neurons into the cell cycle, followed by an uncoordinated progression through the cycle, leads to degeneration of neurons in conditions such as AD. As far as advancing the theory, well, this is the milliondollar question. There are several ways to attempt it:

1. Better studies of human brain, both normal and those afflicted by other degenerative disorders, using rapid postmortem tissue.

2. Development of models based on findings in human brain.

Zsuzsanna Nagy: One of the problems with rapid postmortem analysis is that, most of the time, the brain is not normal. The same goes for biopsy tissues.

\footnotetext{
${ }^{1}$ Note: The transcript has been edited for clarity and accuracy.
}

Karl Herrup: How does the mitotic reentry fit in with other theories? For example, what about the inflammation hypothesis?

Nathaniel Milton: Or what about the amyloid hypothesis? How does amyloid- $\beta(\mathrm{A} \beta)$ fit in?

Mark Smith: Without tying the cell cycle in with our current understanding, we do not have a clue.

Zsuzsanna Nagy: I think the mitotic reentry is not restricted to $\mathrm{AD}$. I think it might be a common path to degeneration that occurs in several different diseases.

Karl Herrup: I agree with Zsuzsanna.

Mark Smith: Zsuzsanna, then do you think cell-cycle reentry is a late event in neurodegeneration, or at least a non-specific event?

Zsuzsanna Nagy: I do not think it is late; I just think that mitotic reactivation on its own is the way neurons degenerate in general. What follows after reentry turns the various conditions into specific diseases.

Ben Wolozin: Yes, so we have three possible suspects: inflammation, $\mathrm{A} \beta$, and, presumably, oxidation. What 
is the temporal progression? Mark, do you not think the cell cycle events come first?

Mark Smith: Ben, yes, I do, and have evidence that the cell cycle comes first (at least before your proposed initiators).

Rachael Neve: Mark, what is your evidence that the cell cycle comes first?

Mark Smith: Rachael, we and others (Inez, Karl, etc.) have looked at temporal progression, and cell cycle events are early.

Karl Herrup: Inez, I like the track you are on. I have been thinking, though, that there may be postmortem events that skew the details of the message we are after (and that means I agree with Zsuzsanna).

Inez Vincent: Our studies of different degenerative disorders have revealed that entry into the cell cycle is not a universal mechanism for degeneration.

Karl Herrup: Of course it is not universal, but it is not unique to $\mathrm{AD}$, either.

Inez Vincent: There is specificity in neurofibrillary tangles (NFT) and other tau-associated disorders.

Gabrielle Strobel: Zsuzsanna, several groups, including yours, have found cell-cycle aberrations in peripheral lymphocytes in $\mathrm{AD}$ patients. Is this connected to AD? Or is this just a reflection of older people's increasing risk of loss of checkpoint control?

Zsuzsanna Nagy: Interesting question, Gabrielle. We are working on it. However, since my control and AD groups were age-matched, the effects seem to be ADrelated rather than a consequence of age.

Ping Lu: I think that the cell cycle might be related to tauopathy.

Inez Vincent: That is an interesting idea, Ping. Perhaps tau is the most vulnerable substrate?

Zsuzsanna Nagy: I must disagree with Inez. Temporal lobe epilepsy is not a tauopathy and has no AD-like features but neurons still degenerate via the cell cycle.

Gabrielle Strobel: Ping, could you give us an example of how conformational changes after phosphory- lation fit into the cell-cycle hypothesis of AD? After phosphorylation of certain Ser/Thr-proline bonds, PIN1 changes their conformation, and then what happens? Could you explain your hypothesis?

Ping Lu: I think that PIN-1-induced conformational changes are important for the cell cycle, oncogenesis, and neurodegeneration, such as tauopathies.

Karl Herrup: But I am with Mark. You can pick up cell cycle changes in the absence of phospho-tau.

Robert Bowser: I agree with Mark and Karl. Cell cycle changes can occur independently of tau phosphorylation.

Zsuzsanna Nagy: It appears that Karl and I agree on the phospho-tau and cell cycle relationship (or the lack of it).

Ping Lu: Tau phosphorylation is a result of cell cycle, through mitotic activation.

Zsuzsanna Nagy: Ping, you have got it right, I think.

Mark Smith: I think the cell cycle has two direct consequences: phosphorylation and oxidative stress. Both of these events lead to accumulation of phosphotau and this (somehow) protects cells. Remember that most neurons that die have no phospho-tau!

Craig Atwood: Yes.

Karl Herrup: Do we think that phospho-tau is a necessary consequence of cell cycle activation?

Nathaniel Milton: If the cell cycle comes first, then phosphorylated tau and $\mathrm{A} \beta$ could be a close second. These may not be essential for all types of neurodegeneration, but maybe for $\mathrm{AD}$.

Ping Lu: PIN-1-induced conformational change is required for dephosphorylation of many MPM-2 epitopes, which may be linked to tau hyperphosphorylation.

Inez Vincent: I would have to refer to Thomas Arendt's idea of neuronal activity-driven processes that may lead to cell cycle activation. He has suggested that a degree of plasticity (a good thing) might eventually lead to activation of the cell cycle and death (a bad thing). 
Ben Wolozin: I would like to throw out a simple hypothesis that might explain much of these phenomena. Intracellular accumulation of $\mathrm{A} \beta$ (or tau) leads to proteasomal inhibition. All of the cell cycle-regulated proteins are also controlled via proteasomal degradation. Hence, as proteasomal inhibition increases, the activity of the cell-cycle regulators increase and the neurons go into a state reminiscent of mitosis. Thus, anything that inhibits the protease might cause this.

Inez Vincent: Any idea, Ben, why this might not happen in the transgenic mouse models that produce abundant $\mathrm{A} \beta$ ?

Ben Wolozin: These animals produce lots of $\mathrm{A} \beta$, but it is extracellular, and the neurons are not damaged until late.

Jan Hallows: Ben, but what leads to the initial activation of the cell cycle prior to the accumulation of tau or $\mathrm{A} \beta$ ?

Ben Wolozin: Jan, I think the simplest explanation is that small $\mathrm{A} \beta$ oligomers or oxidative stress cause the proteasomal inhibition.

Zsuzsanna Nagy: Ben, how do you explain the cell cycle-related death in neurodegenerative disorders that do not have tau or amyloid accumulation?

Ben Wolozin: Many things cause proteasomal inhibition - oxidative stress, aggregated proteins. Hence, one can get to the same phenotype from many directions.

Karl Herrup: I like the proteasome idea in general, but would this not kill a neuron rapidly?

Mark Smith: I think the inhibition of the proteasome comes secondary to oxidative stress.

Zsuzsanna Nagy: I second that, Mark.

Robert Bowser: Inflammatory responses may also activate cell-cycle kinases.

Zsuzsanna Nagy: Can you elaborate on that, Bob?

Robert Bowser: Inflammation activates signaling pathways that can regulate the activity of kinases involved in cell-cycle regulation.
Inez Vincent: Clearly, proteasome activity is critical for cell-cycle progression.

Douglas Feinstein: Could there be a relationship among this proteasomal inhibition, chronic $\mathrm{NF} \kappa \mathrm{B}$ suppression, and the activation of the cell cycle?

Rachael Neve: I think you are on to something there, Douglas.

Douglas Feinstein: Perhaps this brings together aspects of inflammatory activation and the role of $\mathrm{NF} \kappa$ in promoting (or inhibiting) cell proliferation?

Ben Wolozin: Douglas, the connection with the proteasome and $\mathrm{NF} \kappa \mathrm{B}$ is easy, since $\mathrm{I} \kappa \mathrm{B}$, which inhibits $\mathrm{NF} \kappa \mathrm{B}$, is regulated by the proteasome. However, one could also easily explain $\mathrm{NF} \kappa \mathrm{B}$ effects independently of the proteasome because there is so much inflammation in AD.

Nathaniel Milton: Ben, is AD not a phenotype arrived at from many directions?

Ben Wolozin: Nathaniel, I am not proposing that proteasomal inhibition causes $\mathrm{AD}$, just the specific hypothesis that proteasomal inhibition could explain changes in cell-cycle proteins.

Douglas Feinstein: Ben, I absolutely agree. But there could also be long-term, chronic buildups in some other $\mathrm{NF} \kappa \mathrm{B}$-related proteins.

Ben Wolozin: Definitely.

Inez Vincent: Based on the plasticity/neuronal activity idea, it might be toxic metabolites, oxidative damage, DNA damage, or other undetermined factors that may signal this special pathway in selective neurons.

Mark Smith: We have the classic chicken-and-egg situation: What causes what? We have tried oxidative stress, tau phosphorylation, and proteasome inhibition as initiators, but do not see the appearance of all the other aspects. However, once neurons leave the $\mathrm{G}_{0}$ phase of the cell cycle, then we see all aspects appearing in a temporal progression.

Craig Atwood: Cell-cycle reentry also could explain the mitochondrial abnormalities (increased mtDNA and COX-1) seen in pyramidal neurons, and hence, oxidative stress. 
Rachael Neve: Mark, what model system are you using to look at temporal progression? Primary neuronal cultures?

Ping Lu: Can oncogenes be involved in activation of the cell cycle?

Karl Herrup: Ping, I think the answer is, "not likely", since this would seem to necessitate an early genetic change and would be difficult to explain in terms of the large number of neurons that die.

Inez Vincent: I wonder if it is possible that only certain neurons might be susceptible to using cell cycledriven mechanisms in degeneration - for instance pyramidal neurons - whereas neurons of the substantia nigra, cerebellum, etc., do not?

Gabrielle Strobel: Inez, might that have to do with differences in activity/plasticity? How would you test that?

Inez Vincent: Gabrielle, possibly.

Robert Bowser: Inez, degenerative selectivity is probably related to plasticity, though cell-cycle activation may only push the neuron towards a more susceptible state, whereby other factors $(\mathrm{A} \beta$, etc.) may then ultimately lead to its demise.

Zsuzsanna Nagy: Bob, one wonders whether the neuronal populations that enter the cell cycle depend on personal susceptibility or maybe on the nature of the mitogenic stimulus.

Inez Vincent: Yes, Bob. However, cell-cycle activation is prominent in certain other degenerative disorders, such as Niemann-Pick disease, that totally lack amyloid deposition.

Zsuzsanna Nagy: Inez, we found that granule cells with Pick bodies also follow the cell-cycle path.

Craig Atwood: Inez, has not amyloid been shown to deposit with cholesterol in Niemann-Pick disease?

Nathaniel Milton: Inez, do not forget the glial cell cycle.

Karl Herrup: Let us not forget that the evidence for this cell-cycle thing goes way back to the beginnings of the CNS. The breadth of applications to neurodegeneration is thus potentially much wider.

Ping Lu: I agree with Inez. It seems that neurons in certain regions are activated, but not others.

Zsuzsanna Nagy: Ping Lu, I think the neurons involved vary from one disease to another. Maybe individual sensitivities will determine which person gets what type of neurodegeneration.

Mark Smith: Inez, do you think that the initiating event is specific for certain neurons or that only pyramidal neurons develop the phenotype?

Gabrielle Strobel: Current transgenic mice in AD (A $\beta$ PP, presenilin, tau, apoliporprotein E) are all partial models. Have any of them been crossed with transgenic mice used in cell-cycle and cancer research to see if that recapitulates $\mathrm{AD}$ more fully?

Mark Smith: Gabrielle, a nice thought, except that cancer involves successful division; this is something else.

Inez Vincent: Yes, Gabrielle, but it is impossible to ignore the selectivity. And here, activity and perhaps other biochemical features may be important, such as the amount of tau.

Douglas Feinstein: Inez, is there any correlation about which types of neurons are most affected, where they are, what transmitters they express?

Mark Smith: Douglas, I think people are "gun shy" of this after the acetylcholine story.

Douglas Feinstein: Right, Mark, but it might be nice to know. How about COX-2 survival versus cell-cycle entry?

Ping Lu: PIN-1 may be a factor linking cell cycle, AD, and cancer [1].

Karl Herrup: Ping, perhaps you need to spell out your PIN-1 idea a bit more for those of us who have just heard it here.

Ping Lu: PIN-1 is critical for controlling $\mathrm{G}_{1} / \mathrm{S}$ and mitosis. It is required for dephosphorylation of many epitopes of the MPM-2 antibody. PIN-1 is overexpressed in cancer, but its function is inhibited in AD. 
Nathaniel Milton: Mark, is the AD brain we all look at the survival success?

Mark Smith: To some extent, yes, at least those neurons with pathology.

Rachael Neve: I would like to propose that $\mathrm{A} \beta \mathrm{PP}$ is intimately involved in this cell-cycle process. We have shown that $\mathrm{A} \beta \mathrm{PP}$ interacts with the cell-cycle protein $\mathrm{A} \beta \mathrm{PP}-\mathrm{BP} 1$, and that activation of $\mathrm{A} \beta \mathrm{PP}-\mathrm{BP} 1$ can cause neurons to enter the cell cycle [2]. Perhaps as we age, the interaction between $\mathrm{A} \beta \mathrm{PP}$ and $\mathrm{A} \beta \mathrm{PP}-\mathrm{BP} 1$ becomes unregulated. Due to oxidative stress or inflammation, maybe? Just to add to this, we also have evidence that $\mathrm{NF} \kappa \mathrm{B}$ activation inhibits $\mathrm{A} \beta \mathrm{PP}-\mathrm{BP} 1$ 's ability to push neurons into the cell cycle, showing that $\mathrm{NF} \kappa \mathrm{B}$ is neuroprotective in this process.

Craig Atwood: Rachael, yes, A $\beta$ PP-BP1 needs to be further explored.

Inez Vincent: Since Ping mentioned "oncogenes" earlier, I wanted to draw everyone's attention to the fact that the cdc 2 gene lies in the new AD susceptibility region on chromosome 10 !

Karl Herrup: Inez, I would love the connection, but cdc2 is pretty late in the cell cycle, no?

June Kinoshita: Inez, that is interesting! Have you talked to any of the geneticists about this?

Nathaniel Milton: Gene differences in cdc2 have not been linked to AD yet. We are still searching.

Inez Vincent: Great, Nathaniel!

Ping Lu: Plk1 is another oncogene involved in AD [3].

Karl Herrup: How is it involved?

Ping Lu: Plk1 is amplified and hyperactivated in cancer; it is also known to be activated in AD.

Ken Maiese: To add a little more fuel to the fire, especially with neuronal vulnerability, we have found that attempted cell-cycle regulation impacts both the early (membrane asymmetry) and late stages of neuronal injury (genomic DNA injury).

Rachael Neve: Ken, can you elaborate on that? Have you published it?
Ken Maiese: Yes, see Lin et al. [4]. We have shown that exposure to toxic injuries, such as free radicals, leads to progressive neuronal injury over 24 hours. This is accompanied by the rapid induction of the initial phase of programmed cell death that involves the exposure of membrane phosphatidylserine residues. Using the cell-cycle markers bromodeoxyuridine (BrdU) and proliferating cell nuclear antigen (PCNA), we have illustrated that the progressive exposure of membrane phosphatidylserine residues occurs in concert with the attempt by postmitotic neurons to enter the cell cycle. This ill-fated attempt occurs only in the same population of neurons that have begun the initial stages of programmed cell death, suggesting that attempted induction of a latent cell cycle in postmitotic neurons correlates with the early stage.

Mark Smith: Far be it from me to defend the amyloidists, but let us remember that neuronal injury/stress of any kind increases $\mathrm{A} \beta \mathrm{PP} / \mathrm{A} \beta$, so it might be involved in so-called "non-amyloid" conditions [5].

Inez Vincent: That is correct, Mark, and brings the presenilins into the fray, as well!

Rachael Neve: Mark, to support your statement: A simple increase in $\mathrm{A} \beta \mathrm{PP}$ levels causes neurons to enter the cell cycle. We have shown that in our primary neuronal culture model, where overexpression of $\mathrm{A} \beta \mathrm{PP}$ by way of HSV vectors causes DNA synthesis.

Inez Vincent: Rachael, do you think that postmitotic neurons would behave differently from primary neurons?

Rachael Neve: Inez, our primary cultures are largely postmitotic.

Karl Herrup: I still think a neuron that is driven into the cycle will die rather than divide. This implies that the specificity (at least to this type of death) must be in the signal, not in the neuron.

Inez Vincent: I agree, Karl.

Ping Lu: So do I; neurons will die if driven to divide. I think this is a major difference between cancer and AD.

Zsuzsanna Nagy: Rachael, did your neurons actually divide, and, if so, what is the time required for cycle completion? 
Rachael Neve: Our neurons do not divide; they die after showing DNA synthesis. We have shown that inhibitors of DNA synthesis do not prevent the death, but inhibitors of the $\mathrm{G}_{0}-\mathrm{S}$ phase transition do.

Robert Bowser: Zsuzsanna, the nature of the mitogenic stimulus will define the intracellular pathways activated, and thus, the presence of any cell-cycle proteins activated.

Karl Herrup: Bob, I agree.

Inez Vincent: One thing we must then keep in mind is how this "mitogenic" stimulus is propagated to different neurons and brain regions in $\mathrm{AD}$.

Ken Maiese: We have found that a small percentage of neurons enter the cell cycle, but do not succumb to injury. Any thoughts?

Robert Bowser: Ken, I think that a neuron's susceptibility will depend on how far into (if at all) the cell cycle it truly progresses.

Karl Herrup: Ken, I think GABAergic neurons are spared this rule. Does anyone else find that GABAergic neurons in (cortical) cultures behave differently with regard to the cycle?

Inez Vincent: That is interesting, Ken and Karl.

Rachael Neve: Is that right, Karl? Do you find that GABAergic neurons are not susceptible to cell-cycle entry?

Karl Herrup: They are susceptible to cell-cycle entry, just not to cycle-induced death.

Rachael Neve: That is very interesting. I assume you have determined that in a primary neuronal culture, using ICC coupled with BrdU labeling?

Karl Herrup: Yes, the results are from culture.

Inez Vincent: This would certainly need to be followed up with other neurotransmitter-specific lines.

Karl Herrup: I have been trying to find out from a number of pathologists whether GABA neurons are known to be specifically spared or targeted in AD. No answers so far.
Zsuzsanna Nagy: Karl, I do not think it has been looked at yet.

Ken Maiese: Actually, some believe that those neurons that enter the cell cycle but are not injured represent a "greater plasticity" and may function along the same lines as embryonic stem cells [6].

Karl Herrup: Ken, I think you are on to something. I wonder if these cells are not the source of the neurospheres that everyone seems to culture out of adult brain.

Ken Maiese: Karl, that is a possibility. Many questions still exist. We also know that in neuronal models, attempted cell-cycle regulation accounts for approximately 40-50 percent of the neurons injured, so other, more downstream cellular pathways also play a role.

Yuzhi Chen: Dr. Herrup, I like your idea about signaling and neuronal death, and it may be through $\mathrm{A} \beta \mathrm{PP}$.

June Kinoshita: Are there any mouse models in which cell-cycle regulators are expressed in postmitotic neurons.

Ping Lu: June, we may have a mouse model.

Rachael Neve: Pray tell, Ping!

June Kinoshita: Yes!

Zsuzsanna Nagy: What have you got, Ping?

Ping Lu: The PIN-1-related mouse model.

Rachael Neve: What do you mean by that?

Inez Vincent: In Niemann-Pick disease Type C, we have found that Purkinje neurons contain hyperphosphorylated tau and mitotic proteins. These cells die very early in the disease, but never form NFT. I believe a similar mechanism operates in them and they die, but without forming NFT [7].

Craig Atwood: Inez, for amyloid in Niemann-Pick Type C cells, see Yamazaki et al. [8].

Karl Herrup: Inez, have you looked at ataxiatelangiectasia? 
Inez Vincent: I would love to look at ATM, but no time! But June, producing a cell-cycle model in brain is going to be difficult, and may have to be approached sort of wildly.

Robert Bowser: June, I have looked at changes in retinoblastoma and $\mathrm{E} 2 \mathrm{~F} 1$ in $\mathrm{A} \beta \mathrm{PP}$ and SOD1 transgenic mice. We have not seen any changes in the $\mathrm{A} \beta \mathrm{PP}$ transgenic mice, and little neuronal cell death occurs in these animals. However, we did see changes in the SOD1 mice prior to the onset of motor neuron cell death.

Ken Maiese: Bob, I definitely agree with you. We find, though, that the cells appear to stop prior to $G_{1}$, similar to several other published reports.

June Kinoshita: Bob, just to be clear, you did see cellcycle gene expression in SOD1 mice prior to neuronal degeneration?

Robert Bowser: June, yes, prior to and concurrent with mitochondrial vacuolation. We are currently following up these observations and hope to better define the temporal pattern and relationships (if any) to cell death.

Inez Vincent: Some of you may hate me for saying so, but it really is not possible to use neuronal cultures (even if they are "differentiated") as models for cell cycle-mediated degeneration, per se. Primary neurons and neuronal cell lines are sustainable in cell culture primarily because of their cell-cycle abnormalities. It would be far too difficult to interpret results obtained with these cultures in the context of cell cycle-mediated events in mature, differentiated neurons of brain. This does not mean that neuronal cultures are not useful for studying many other aspects of neuronal death, for example, cytoskeletal abnormalities, oxidative damage pathways, and other signaling pathways.

Zsuzsanna Nagy: I agree with Inez there, unfortunately.

Glenda Bishop: Inez, if neuronal cultures are not good models, what would be?

Karl Herrup: Inez, I think the problem is not with the culture, per se, but with the fact that we use embryonic neurons as the source of our cultures.
Nathaniel Milton: Inez, we need the right mouse model for AD. A $\beta$ PP transgenics are not perfect.

Karl Herrup: If we could culture adult, isolated neurons, we might make new progress.

Inez Vincent: I agree with Nathaniel and Karl.

Ken Maiese: Inez, I agree, all models have their drawbacks, but we use primary cultures, not cell lines. Obviously, the knowledge gathered from cultures must be translated into animal models.

Rachael Neve: I think neuronal culture models give a good first approximation, which can then be tested in vivo.

Ping Lu: I think mouse models will be a better choice.

Gabrielle Strobel: Toward better in vivo models: Would it be useful to modify expression of various cell-cycle genes in tau-transgenic Drosophila to make a more faithful model of neurodegeneration? Or create other Drosophila models?

Zsuzsanna Nagy: I do not like the Drosophila idea.

Gabrielle Strobel: Why not?

Zsuzsanna Nagy: I think it is a bit far away from what we are trying to find. Call me old-fashioned!

Mark Smith: Greg Brewer has a technique to culture adult neurons. He claims even to get them to divide. The data/video are spectacular [9]!

Zsuzsanna Nagy: Karl, what about the Brewer method? Have you tried it?

Karl Herrup: We have tried the Brewer technique without success. I have seen the video and wonder if these are the GABA neurons.

Zsuzsanna Nagy: We did not have much luck with the method either. That is why I asked.

Inez Vincent: The Brewer technique works, but only because the cells are not truly postmitotic. How then, can one study cell cycle-associated mechanisms in such cells? The real challenge is turning on the cell cycle in a real postmitotic neuron in vivo. 
Nathaniel Milton: A leading journal editor suggested I use cdc2 knockouts. Any better ideas?

Ping Lu: A cdc2 knockout is likely lethal?

Gabrielle Strobel: I noticed an interesting letter by David Smith, Zsuzsanna, and others reporting that cyclin $\mathrm{E}$ is upregulated in hippocampus in people with elevated homocystine and AD [10]. Any thoughts?

Inez Vincent: This is a great study. I hope there will be a follow-up?

Zsuzsanna Nagy: I am working on it.

Karl Herrup: Gabrielle, Mark and I talk about the difference between a toxic response and a protective one. Both will come up in a disease state, but you only want to inhibit the latter.

Mark Smith: Inez, I think there is a big difference between a conventional cell cycle and a cell cycle in a postmitotic neuron. To study AD, we should look only at the latter and, therefore, need postmitotic cells.

Ping Lu: Mark, I agree that an AD cell cycle is different from the conventional cell cycle.

Zsuzsanna Nagy: I agree with Mark, but then we are back to the initial question: How to look at it?

Inez Vincent: The best, but also most difficult system to study is a postmitotic neuron in brain.

Karl Herrup: Ping, Mark, I think the early cycle events are perfectly traditional; they just hit a road block and cannot move on.

Mark Smith: If that is so, then why do we see $G_{1}$ markers simultaneously with S markers [11]?

Ping Lu: I do not think early cell-cycle events are all normal.

Ken Maiese: Ping, I agree. It appears that induction of the cell cycle in neurons can lead to other events associated with caspase activation.

Inez Vincent: Our work supports Karl's explanation. Neurons simply cannot get through mitosis.
Craig Atwood: Why the roadblock? Problems with cytokinesis?

Zsuzsanna Nagy: Craig, I think cytokinesis is the final block only.

Karl Herrup: Craig, DNA breaks are my guess (which might please the oxidation folks).

Gabrielle Strobel: Craig, or accumulated DNA damage and impaired ability to repair?

June Kinoshita: There is an assumption that the expression of cell-cycle genes in postmitotic neurons is an ectopic event, but do we know that for sure? Has the possibility that they have some other function (perhaps at a lower level of expression) in postmitotic neurons been ruled out?

Rachael Neve: June, that is a very good point. I wonder if these cell-cycle proteins that are in neurons are not involved in normal neuronal plasticity. Quite a bit of evidence coming out to support that idea.

Ben Wolozin: Rachael, I agree. Understanding this is essential because it helps to determine whether one wants more cell-cycle activation or less. The answer is not clear.

June Kinoshita: Rachael caught the subtext of my question. Any thoughts from others?

Mark Smith: June, always a possibility, since cellcycle proteins have other functions. Not clear.

Karl Herrup: June, I have not heard of any use for mitotic events in postmitotic neurons. But I could be persuaded.

Rachael Neve: Karl, for example, there are data showing that there is increased neurogenesis with learning; also, some forms of plasticity such as ischemia and drug abuse cause changes in cell-cycle proteins.

Karl Herrup: True Rachael, but the increased neurogenesis is in a normally dividing stem cell population. I do not know the drug abuse data.

Rachael Neve: The drug abuse data are out of Eric Nestler's lab (University of Texas Southwestern Medical Center, Dallas Texas). 
Inez Vincent: My response to June's comment is that we need to launch a serious study of cell-cycle proteins in normal human brain so we better understand the picture in a normal neuron. These proteins have not been previously studied in brain, and so we know nothing about what they might be doing in normal neurons.

Rachael Neve: I agree.

Jan Hallows: Perhaps the roadblock to actual mitosis is that activation of cell-cycle proteins does not occur in a coordinated fashion.

Mark Smith: Agreed.

Nathaniel Milton: Nuclear versus cytoplasmic actions of cell-cycle kinases need to be assessed.

Rachael Neve: And actions at the synaptic terminal, as well.

Robert Bowser: Cell-cycle proteins in the nucleus likely participate in regulating not only gene expression, but also chromatin structure. Therefore, changes in nuclear cell-cycle proteins could also modify chromatin structure and make neurons more susceptible to DNA injury.

Karl Herrup: Nathaniel and Bob, I think this is getting down to it. A lot may ride on localization of these compounds.

Mark Smith: Bob, chromatin remodeling is certainly an issue that we are looking at closely.

Gabrielle Strobel: But are not many of the observed cell-cycle proteins in the cytoplasm, not in the nucleus?

Inez Vincent: That is correct, Gabrielle.

Karl Herrup: We find them there in postmortem material, but were they the result of the agonal state?

Nathaniel Milton: Phosphorylated $\mathrm{A} \beta$ and tau are cytoplasmic events.

Zsuzsanna Nagy: Exactly. It appears that while they relate to cell-cycle events when localized in the nucleus, the cytoplasmic localization may actually be related to something else, such as tau phosphorylation.
Robert Bowser: Karl and Nathaniel, there are definitely changes in subcellular distribution of many of these proteins, some of which are not typical for cellcycle functions. So further defining function versus distribution is important to determine how these proteins function in protective versus degenerative pathways.

Gabrielle Strobel: Chromatin remodeling is also being looked at intensely in Huntington's.

Zsuzsanna Nagy: Gabrielle, yes, but I personally take extreme care to make sure we only look at nuclear localization in relation to cycling.

Rachael Neve: What do you mean by that, Zsuzsanna?

Zsuzsanna Nagy: I mean that cdks might drive cell division in the nucleus, but if they do not translocate there, they might go on phosphorylating whatever is at hand in the cytoplasm.

Craig Atwood: When a cell divides, what happens to the nuclear membrane?

Karl Herrup: Craig, in normal division the nuclear membrane dissolves in $\mathrm{M}$ phase.

Craig Atwood: Maybe it has dissolved earlier?

Inez Vincent: Craig, the nuclear membrane typically dissolves and reforms once cytokinesis is complete. There are no such signs of nuclear membrane changes in $\mathrm{AD}$ brain, even in neurons containing full-blown NFT.

Craig Atwood: Well, something must be wrong! Or are the data artifactual?

Nathaniel Milton: If tau and $\mathrm{A} \beta$ phosphorylation are behind AD pathology, we need chemicals which only block these events and not cell cycle, i.e., substrate specific-inhibitors.

Mark Smith: Nathaniel, only if tau and $\mathrm{A} \beta$ are BAD!

Nathaniel Milton: Phosphorylated $\mathrm{A} \beta$ is BAD - very, very BAD.

Mark Smith: I continue to smile!

Nathaniel Milton: Mark, you obviously do not have any phosphorylated $\mathrm{A} \beta$. 
June Kinoshita: To elaborate on Ben's simple scenario [mentioned a while back], perhaps a neuron under stress is expressing cell-cycle proteins to carry out some plasticity-related functions, but they build up because $\mathrm{A} \beta$ is gumming up the proteasomal system, and reach a level where they drive the neuron into mitosis?

Mark Smith: June, I respectfully disagree with your sequence of events [12].

Ping Lu: June, that is a good summary.

Karl Herrup: June, I am not sure I can buy into this one completely. There still needs to be a trigger and a source of specificity.

Rachael Neve: I like your thought, June, all except for the $\mathrm{A} \beta$ part.

Inez Vincent: I am with Rachael!

Ben Wolozin: Rachael, why do you not like the $\mathrm{A} \beta$ part?

Rachael Neve: Ben, you made me laugh out loud!

Nathaniel Milton: $\mathrm{A} \beta$ could be an effect, not the cause.

Zsuzsanna Nagy: Nathaniel, I like that one.

June Kinoshita: Well, I am trying to mediate among all the camps. Everyone gets to play a role, but not everyone can be the star!

Gabrielle Strobel: Zsuzsanna, your diagnostic test based on $\mathrm{G}_{1} / \mathrm{S}$ control in lymphocytes: At what stage is that? Is a company developing it?

Zsuzsanna Nagy: Gabrielle, there is no definite answer to that one, yet. Are you interested?

Gabrielle Strobel: I will be interested in taking it in 20 years! In the test, are AD and control groups completely separate, or do they overlap somewhat?

Zsuzsanna Nagy: There is a small overlap. We are trying to figure that one out. It might have to do with the age-related changes we talked about earlier. To be useful, the test will have to have an age correction, somehow.
Rachael Neve: Which of the mouse models have been studied extensively for evidence of DNA synthesis? All of them? All without positive data?

Inez Vincent: I have not seen any studies of DNA synthesis in vivo-very difficult to do.

Rachael Neve: Karl's done it [13]!

Nathaniel Milton: Zsuzsanna, but what is the cause? Cdc2?

Zsuzsanna Nagy: Nathaniel, It might be cdc 2 or cdk2. That is what I believe, anyway.

Nathaniel Milton: $\mathrm{Cdc} 2$ is on chromosome 10 in the $\mathrm{AD}$ region. That is my choice.

Zsuzsanna Nagy: Nathaniel, yes, I heard Inez Vincent mention it before. I am looking forward to some reprints.

Inez Vincent: Karl mentioned earlier that it probably does not start with cdc2. At least in the cell cycle, gene expression is often coordinated. Whether this is true of neurons needs to be determined.

June Kinoshita: Zsuzsanna, you mentioned that cellcycle regulators are expressed in epileptic neurons. The mouse models for epilepsy should be pretty good. Has anyone looked at them?

Zsuzsanna Nagy: June, I think there were some studies, but I have not followed them closely.

Gabrielle Strobel: A basic question: Neuronal loss in AD starts in the entorhinal cortex and then proceeds in a fairly predictable anatomical pattern. Does the expression of cell-cycle markers match this pattern?

Inez Vincent: We looked at the brains of Huntington's disease victims. Did not find any cell-cycle aberrations. We have unfortunately not had access to the entorhinal region. If someone is willing to send me the tissue, I would love to do that.

Mark Smith: Gabrielle, the cell cycle precedes, in my opinion.

Gabrielle Strobel: Mark, I understand, but do cellcycle aberrations also proceed through the brain in the anatomical patterns seen for the neurodegeneration? 
Zsuzsanna Nagy: Gabrielle, I do not know of a systematic study, but in Down's syndrome brains, we find the cell cycle-related protein expression in areas where $\mathrm{AD}$ will develop for sure later [14].

Ken Maiese: Zsuzsanna, that is very interesting. Can you elaborate on the time frame of this?

Zsuzsanna Nagy: Ken, Down's patients develop AD when they are about 30-40 years. The cell-cycle markers appear when they are in their teens [14].

Karl Herrup: Zsuzsanna, is this published? That is a great finding.

Ken Maiese: Zsuzsanna, how do you know that there exists a specific causal relationship? I realize, at this time, this is more of a hypothetical question, but as I mentioned before, we do not find that all cell-cycle induction in neurons leads to injury.

Zsuzsanna Nagy: Ken, I think that depending on the age of the rat, you might find differences in neuron behavior and survival after mitogenic stimulation.

Inez Vincent: Zsuzsanna brings up a good point. The duration of the changes make it very difficult to study prospectively.

Zsuzsanna Nagy: What model did you use?

Ken Maiese: We use primary rat neurons.

June Kinoshita: Everyone, this has been very lively and informative. Can you propose some priority research questions to move this whole area of inquiry forward?

Karl Herrup: June, I think what we need are models. Culture or on the hoof. Right now, our mice are letting us down when it comes to neuron death.

Ben Wolozin: I agree with Karl 300 percent (or $\$ 100,000$ worth of agreement). One cannot study this issue in a causative, hypothesis-driven model unless there is a good animal model that recapitulates the cellular changes in $\mathrm{AD}$. The P301L tau x $\mathrm{A} \beta$ model might be the best. Then one can ask what happens if the cell-cycle changes are blocked.

Inez Vincent: I would like to suggest sharing tissues so a variety of different markers may be followed in the same cases and the results more meaningfully interpreted. I wish Steve Snyder were around to make an offer either of organizing this or paying for it.

Mark Smith: Inez, I can help you on this.

Inez Vincent: Awesome, Mark!

Nathaniel Milton: If we knock out the cell-cycle inhibitors, do we increase, reduce, or have no effect on neurodegeneration?

Karl Herrup: Nathaniel, good question.

Ping Lu: Some cell-cycle inhibitors have been knocked out. Some sections of brain are bigger (p27).

Inez Vincent: Next step: Let us get together to discuss a more comprehensive model for studying cell-cycle changes in vivo. I have a few ideas and am working on some.

Gabrielle Strobel: As we have reached the end of the hour, I want to thank everyone for participating.

June Kinoshita: Yes, thank you all very much for attending today's chat.

Inez Vincent: June, Gabrielle, and Nico - thanks for taking the initiative in organizing this chat.

\section{References}

[1] P.J. Lu, G. Wulf, X.Z. Zhou, P. Davies and K.P. Lu, The prolyl isomerase Pin1 restores the function of Alzheimer-associated phosphorylated tau protein, Nature 399 (1999), 784-788.

[2] Y. Chen, D.L. McPhie, J. Hirschberg and R.L. Neve, The amyloid precursor protein-binding protein APP-BP1 drives the cell cycle through the S-M checkpoint and cause apoptosis in neurons, J Biol Chem 275 (2000), 8929-8935.

[3] P.L.R. Harris, X. Zhu, C. Pamies, C.A. Rottkamp, H.A. Ghanbari, A. McShea, Y. Feng, D.K. Ferris and M.A. Smith, Neuronal polo-like kinase in Alzheimer disease indicates cell cycle changes, Neurobiol Aging 21 (2000), 837-841.

[4] S.H. Lin and K. Maiese, The metabotropic glutamate receptor system protects against ischemic free radical programmed cell death in rat brain endothelial cells, J Cereb Blood Flow Metab 21 (2001), 262-275.

[5] S.R. Robinson and G.M. Bishop, $\mathrm{A} \beta$ as a bioflocculant: implications for the amyloid hypothesis of Alzheimer's disease, Neurobiol Aging 23 (2002), 1051-1072.

[6] T. Arendt, Disturbance of neuronal plasticity is a critical pathogenetic event in Alzheimer's disease, Int J Dev Neurosci 19 (2001), 231-245. 
[7] B. Bu, H. Klunemann, K. Suzuki, J. Li, T. Bird, L.W. Jin and I. Vincent, Niemann-Pick disease type $C$ yields possible clue for why cerebellar neurons do not form neurofibrillary tangles, Neurobiol Dis 11 (2002), 285-297.

[8] T. Yamazaki, T.Y. Chang, C. Haass and Y. Ihara, Accumulation and aggregation of amyloid beta-protein in late endosomes of Niemann-pick type C cells, J Biol Chem 276 (2001), 4454 4460.

[9] G. Brewer, Regeneration and proliferation of embryonic and adult rat hippocampal neurons in culture, Exp Neurol 159 (1999), 237-247.

[10] Z.S. Nagy, M.Z. Smith, M.M. Esiri, L. Barnetson and A.D. Smith, Hyperhomocysteinaemia in Alzheimer's disease and expression of cell cycle markers in the brain, J Neurol Neurosurg Psychiatry 69 (2000), 565-566.
[11] R. Bowser and M.A. Smith, Cell cycle proteins in Alzheimer's disease: plenty of wheels but no cycle, J Alzheimer's Disease 4 (2002), 249-254.

[12] M.A. Smith, G. Casadesus, J.A. Joseph and G. Perry, Amyloid$\beta$ and $\tau$ serve antioxidant functions in the aging and Alzheimer brain, Free Radic Biol Med 33 (2002), 1194-1199.

[13] Y. Yang, D.S. Geldmacher and K. Herrup, DNA replication precedes neuronal cell death in Alzheimer's disease, $\mathrm{J} \mathrm{Neu}$ rosci 21 (2001), 2661-2668.

[14] Z. Nagy, M.M. Esiri and A.D. Smith, Expression of cell division markers in the hippocampus in Alzheimer's disease and other neurodegenerative conditions, Acta Neuropathol 93 (1997), 294-300. 